\title{
VOCES FOTOGRÁFICAS: EL USO DE LA IMAGEN EN PROYECTOS DE COMUNICACIÓN Y DESARROLLO EN EL SUR DE BOLIVIA
}

\section{Photo-Voices: The Use of the Photographic Image in Communication and Development Projects in the South of Bolivia}

\author{
Mónica Eliana García Gil*
}

Gregory P. Spira**

Recibido: 12 de febrero de 2008 - Revisado: 10 de marzo de 2008 - Aceptado: 28 de abril de 2008

\section{Resumen}

Este texto aborda el uso de la imagen fotográfica como herramienta de investigación en Ciencias Sociales, especialmente en proyectos de comunicación y desarrollo, tomando como punto de partida la imagen, no sólo como medio para recolectar información sino también como parte activa del proceso de investigación, en el cual la fotografía puede impulsar procesos de autorreconocimiento y de transformación social. Asimismo, se desarrolla el planteamiento metodológico de Photovoice (foto voz o voz fotográfica) y, finalmente, se presentan algunos resultados del proyecto participativo denominado Chaicuriri por el Objetivo, experiencia desarrollada en Bolivia que posibilitó a los habitantes de una zona rural establecer sus propias nociones de desarrollo comunitario a partir del uso de la fotografía.

\footnotetext{
Magíster en Comunicación Televisiva de la Universidad Pontificia Bolivariana y candidata a magíster en Comunicación de la Pontificia Universidad Javeriana. Comunicadora Social-Periodista, docente del Área Audiovisual en distintas universidades de Bogotá. Actualmente es docenteinvestigadora de la Facultad de Comunicación Social para la Paz de la Universidad Santo Tomás, sede Bogotá, e integrante del grupo de investigación Comunicación, Paz/Conflicto, de la misma universidad y del grupo Pedagogía Urbana y Ambiental de la Universidad Pedagógica Nacional. Responsable de la asignatura de Comunicación Visual en la Universidad Santo Tomás. Productora, guionista y realizadora de videos institucionales y educativos. Correo electrónico: monigarciagil@yahoo.com.

** Master in Professional Communication (Royal Roads University. Victoria, Canadá) Licenciado en Historia Latinoamericana y consultor de comunicación en Canadá. Es cofundador de Colmagen, oficina de consultoría en Comunicación y Desarrollo Económico que asesora a diferentes ONG, gobiernos municipales y regionales en Canadá y América Latina. Se ha especializado en el uso de medios de comunicación para aumentar la participación popular y lograr cambios sociales. Docente de Historia Latinoamericana en Georgetown University (Washington, DC) entre 1997 y 1999. Fotógrafo profesional especializado en paisajes y retratos. Sus trabajos fotográficos y artículos sobre el proyecto Chaicuriri por el Objetivo y la situación política boliviana han sido publicados en varias revistas canadienses. Correo electrónico: spirag@telus.net.
} 


\title{
Palabras clave
}

Comunicación y desarrollo, imagen fotográfica, Photovoice, investigación a través de imágenes, investigación social, transformación social.

\begin{abstract}
This text approaches the use of the photographic image as investigation tool in Social Sciences, especially in projects of Communication and Development, taking as starting point the image not only as mean to gather information but like active part of the investigation process where the picture can impel self-recognition processes and of social transformation. It is also developed the methodological position of Photovoice (Picture voice or photographic voices) and finally it is shown up some results of the participatory denominated project "Chaicuriri for the Objective", experience developed in Bolivia that facilitated the inhabitants of a rural area to establish their own concepts of community development starting from the use of the photography.
\end{abstract}

\section{Key words}

Communication and development, photographic image, Photovoice, investigation through images, social investigation, social transformation.

\section{Introducción}

De acuerdo con Feliciano F., habitante de Chaicuriri, "ahora tenemos la prueba para mostrar lo que queremos. Las fotos son un reflejo de nuestra realidad y de nuestro futuro". De esta manera expresa el impacto real de Photovoice en su comunidad y su percepción sobre las posibilidades del proyecto, desarrollado a partir de la fotografía, para realizar transformaciones considerables, generadas y supervisadas por la misma comunidad, que permitan mejorar la situación actual de los habitantes de esta zona andina en el sur de Bolivia.

Ante tal expresión, surge la pregunta: ¿es posible generar procesos de transformación social y de desarrollo a través de la fotografía? Hasta el momento, este cuestionamiento parece no haber sido resuelto en su totalidad desde la fotografía (como técnica, arte o profesión) ni desde las Ciencias Sociales. Lo que sí es posible afirmar es que cada vez más la fotografía adquiere mayor importancia en la construcción de formas de ver el mundo y de las personas verse a sí mismas, en distintos grupos sociales y comunidades de diversas regiones, credos y culturas, al tiempo que contribuye a la construcción de imaginarios sociales, entendidos como el banco de imágenes y el modelo de mundo que asume un grupo humano para conformar su identidad y consistencia social (Zeccheto, 2003).

A través de la fotografía no sólo es posible acercarse (y adentrarse) a la concepción estética y ética de una comunidad y llegar a conocer su posición frente a determinadas situaciones y temas, como los valores, las normas, las jerarquías, los roles de las distintas personas en la vida cotidiana y las prioridades, entre otros, sino también identificar fortalezas, debilidades, miedos, deseos y problemáticas de las comunidades involucradas en proyectos de investigación que tienen como eje el uso de la imagen fotográfica, a fin de posibilitar también el autorreconocimiento, establecer y reafirmar una noción de desarrollo y del bien común acorde con sus necesidades y condiciones reales, no supeditadas a miradas externa con intereses, muchas veces, colonialistas, que no reconocen interlocución (verdadera) con los individuos de la población con la que se trabaja. 
Al vincular la imagen fotográfica a procesos de investigación social que impliquen la búsqueda de una noción de desarrollo, se concibe a la imagen no sólo como un resultado, sino también como parte activa de un proceso que va más allá de la denuncia de situaciones y contribuye al acercamiento crítico a realidades sociales concretas, así como a la reflexión y discusión en torno a éstas, con la participación de las personas de la comunidad desde sus propias miradas y percepciones.

Desde el campo de la comunicación y el desarrollo se brinda apoyo a los habitantes de distintos países, principalmente en vías de desarrollo, en cuanto al uso de herramientas comunicativas variadas que les permita expresar sus propios mensajes, mejorar su vida cotidiana, concientizar a sus conciudadanos acerca de la necesidad de lograr cambios sociales y formarlos para encontrar el camino que les permita obtener los resultados esperados. El uso de los medios "populares", además de los medios tradicionales y las nuevas tecnologías de la información y la comunicación, ha proporcionado oportunidades para que las comunidades se expresen de modos que han sido culturalmente relevantes e, incluso, han trascendido las fronteras. Hasta hace poco, los especialistas en temas de comunicación solían, en la mayoría de los casos, determinar la presentación y el contenido de los mensajes comunitarios. En este contexto, la fotografía, como base sustancial del método Photovoice, surge como un medio alternativo para capacitar a los individuos en el proceso de realizar su propio registro visual. Después, los resultados fotográficos son utilizados para iniciar diálogos que logran un análisis crítico frente a la realidad social, política y económica en la que están inmersos, aun con sus contradicciones. Entonces, la fotografía resulta ser una forma alternativa con la cual una comunidad puede evaluar, analizar y expresar su propia visión de lo que significa "el desarrollo".

En este artículo se presentan antecedentes y propuestas relacionados con el uso de la imagen como herramienta de investigación en Ciencias Sociales, y concretamente su aplicación en el proyecto de comunicación y desarrollo Chaicuriri por el Objetivo, basado en el método Photovoice. Como resultado de esta experiencia, los participantes tomaron más de 2.000 fotos y compartieron varios días en discusiones de grupo, exploraron temas que incluyeron modos de aumentar la productividad agrícola, cuidar el ganado, proteger el futuro de los niños, cuidar las reservas naturales, valorar la importancia de la educación y la asignación equitativa de las tareas a las mujeres de la comunidad, entre otros; algunos de los resultados se publican a continuación. Lo anterior, se realizó a partir de una postura crítica frente a los temas que consideraban de mayor importancia, a fin de delimitar las posibles formas en que tanto los actores de la comunidad como las personas externas a ellos (investigadores, funcionarios públicos, entre otros) podrían comenzar a trabajar en planificar y ejecutar soluciones acordes con lo detectado en el proceso investigativo.

\section{La fotografía como objeto y herramienta de investigación}

En el ámbito investigativo, desde que la fotografía y el cine tuvieron aplicación en la antropología y la etnografía visual, la imagen se debe entender no sólo como simple instrumento que permite almacenar, comprobar y verificar datos, sino también como objeto y estrategia que posibilita el análisis y la reconstrucción de la realidad, así como diferentes lecturas sobre ésta.

Abordar la imagen fotográfica como construcción narrativa y objeto de la investigación social requiere reconocer sus potencialidades técnicas, estéticas y expresivas, las cuales permiten construir relatos que apuntan a profundizar, explicar e, incluso, cuestionar los hallazgos obtenidos por medio de las mismas imágenes.

A su vez, el uso de la fotografía en la investigación permite conseguir evidencias frente a las situaciones o problemáticas que son estudiadas, obtener distintos 
puntos de vista frente a un mismo tema, así como observar y comprender comportamientos y los hechos a los que de otra manera sería imposible acceder, incluyendo factores ambientales, anímicos y expresivos que pudieran afectar o intervenir en el desarrollo de la investigación. Asimismo, permite documentar procedimientos, rituales y formas de desempeño de los individuos o grupos de personas observadas, con la mínima intervención en su cotidianidad.

Incorporar la imagen fotográfica a los procesos de investigación implica, entre otros aspectos, una redefinición de roles, tanto de los investigadores como de los participantes, en los procesos de indagación, observación y descripción de situaciones y comportamientos sociales, en los que no se asumen posturas jerárquicas. De esta manera, el investigador pasa a ser un coordinador y un facilitador del proceso, y las personas participantes del estudio asumen el rol de sujetos activos que proponen y establecen sus propias miradas, orientaciones y perspectivas frente a los asuntos tratados. Las mismas personas son quienes aportan en la definición del rumbo de las dinámicas propuestas, y a través de las imágenes es posible validar lo planteado por los participantes del estudio y lo observado por los investigadores-facilitadores.

A fin de evitar que en el proceso prime la subjetividad, ya sea de los fotógrafos o de los investigadores, se debe plantear la fotografía como un proceso dialógico, en el que investigadores y actores sociales participan en autoría conjunta (Buxó, 1999). Esto significa que el investigador, desde su labor como facilitador, es parte de la construcción visual de la realidad cultural, como también lo es el habitante del lugar.

Con respecto al uso de la imagen en la investigación social, se afianza la tendencia que acepta que la fotografía no es una reproducción fiel de la realidad, y cada vez se reconoce más la mediación del investigador-fotógrafo frente al hecho que investiga y registra con su cámara. Desde esta perspectiva, la fotografía no es solamente una manera de observar, estudiar y analizar el mundo a través de imágenes fijas, con una cierta distancia por parte del investigador que busca transmitir una supuesta "objetividad", sino también es, en ella misma, una creación. Al aceptar que la fotografía crea una nueva realidad a partir de la mirada del fotógrafo, se llega a reconocer que "Las fotos explican, hacen sentir algo y ordenan el conocimiento. Son tres procesos de elaboración del conocimiento importantes. Suponen una forma peculiar de conocer la realidad social; pero también de crearla" (Buxó, 1999, p. 27).

Inmersa en el contexto de la comunicación social, vale la pena destacar el carácter de la imagen como creación simbólica, expresada a través de códigos que pueden ser decodificados y susceptibles de ser interpretados e incorporados en el imaginario de individuos y comunidades. La imagen, comprendida desde su dimensión de producto simbólico de una época o cultura, puede ser sistematizada, analizaday, asimismo, conducir al estudio de situaciones, relatos y discursos, que finalmente sitúan las cosmovisiones y el modelo de mundo que asume un grupo humano para conformar su identidad, expresar su sentir frente a los hechos que lo rodean e identificar sus problemáticas y fortalezas, entre otros. En este sentido es importante reconocer que una foto nunca es inocente, pues tiene distintos niveles de realidad y se transforma de acuerdo con la mirada, según quién la observe y desde dónde lo haga. El significado de la fotografía es, entonces, construido por quien la toma y quien la ve, ambos como representantes de posiciones sociales e intereses frente al acto fotográfico.

Desde su metodología, la relación entre la fotografía y los procesos de investigación debe privilegiar la formación de un espíritu crítico, para enfrentar la realización de diversos materiales visuales, ya sean de género informativo, documental u otros, a partir de los debates, la recolección de material con distintos enfoques y distintas fuentes, y la construcción conjunta de conocimiento entre los investigadores-facilitadores y los participantes. 


\section{Photovoice como método participativo para impulsar procesos de comunicación y desarrollo}

En el marco de proyectos de comunicación y desarrollo, documentar las percepciones que una comunidad tiene acerca de los asuntos que afectan su vida no tiene que restringirse exclusivamente a los métodos tradicionales basados en la oralidad y la escritura. En muchos contextos sociales o culturales, independientemente del nivel de alfabetización de la comunidad, la imagen visual está cobrando mayor importancia que los documentos escritos.

Para la cultura occidental, la palabra escrita es portadora de un carácter significativo en cuanto a la objetividad y exactitud que ofrece; además, es importante reconocer que el conocimiento dominante de las sociedades occidentales se sustenta en aquellas observaciones "científicas" y empíricas que han sido codificadas en los textos impresos. Con frecuencia, el conocimiento no impreso es descartado en el marco de lo que se ha denominado "la hegemonía de textocentrismo" (Singhal \& Rattine-Flaherty, 2006 p. 314), y cuando las imágenes suelen aparecer en documentos con texto, normalmente ocupan un papel secundario o de apoyo a la palabra escrita (Kress \& Van Leeuwen, 1996).

A fin de invertir este enfoque centrado en la primacía del texto y en la búsqueda de métodos de investigación que lleguen a un mayor número de personas de distintas culturas, no necesariamente occidentales, han surgido varios métodos basados en la imagen fotográfica, cinematográfica y videográfica, principalmente a partir de los años treinta, cuya aplicación ha tenido eco tanto en Norteamérica como en América Latina y Europa. Con mayor frecuencia, los investigadores sociales comenzaron a incorporar la fotografía, el cine y luego el video para documentar la vida de Ios "otros", objeto de su estudio. Con estas imágenes los investigadores pretendían captar la realidad de un lugar o de un grupo de personas para comunicarlo a otros fuera de allí.
Con los años, y el surgimiento de teorías que apoyan nuevos usos para las tecnologías de la comunicación (visuales y audiovisuales) en distintos contextos, entre ellos los marginales o en vías de desarrollo, las concepciones sobre el uso de la imagen en la investigación también han cambiado. Entre los cambios más relevantes, se destaca el paso de la imagen de instrumento para el registro de información a objeto de la investigación, como parte activa del proceso, $y$ la posibilidad de que las personas involucradas (no investigadoras) sean agentes partícipes en su propio proceso de evaluación y de diagnóstico, a fin de identificar y establecer sus propias necesidades.

El método Photovoice se inscribe en esta nueva corriente que busca, a través de imágenes, desarrollar proyectos participativos, en los cuales los sujetos protagonistas de la investigación sean quienes puedan identificar, representar y ayudar a mejorar a su comunidad, a través del uso de la técnica fotográfica. De esta forma, es posible ampliar las visiones y las experiencias de las personas que participan de esta metodología.

La metodología Photovoice (foto voz o voz fotográfica) fue desarrollada por Caroline C. Wang y Mary Ann Burris, en comunidades rurales de China, en 1994; se basaron en los principios de la educación para la conciencia crítica, desarrollados por Paulo Freire (1970), a través de los cuales se promueve el cambio individual, la calidad de vida de la comunidad y los cambios de las políticas que apuntan a lograr la equidad social. En términos de Freire, la fotografía puede ser entendida como un medio que puede ser usado para posibilitar que una comunidad se mire a sí misma y pueda revelar la realidad social y política en la que está inmersa y su influencia en la vida de las personas (Wang, 2005).

Wang y Burris diseñaron su primer proyecto Photovoice en la provincia de Yunnan, zona rural de China, como medio para llevar a cabo una evaluación más amplia, en términos cualitativos, de la salud de la mujer. Las sesenta mujeres chinas que participaron en el 
proyecto fueron denominadas por las investigadoras como "antropólogas visuales", y fueron ellas quienes fotografiaron los aspectos de su vida cotidiana y, posteriormente, compartieron las imágenes capturadas con otros participantes, con mujeres dirigentes y con funcionarios gubernamentales. La discusión que siguió a esta actividad permitió explorar los temas comunes identificados sobre la salud de la mujer.

Este tipo de investigación también busca influir en la formulación de políticas públicas y, para tal fin, los investigadores organizan exposiciones fotográficas y debates con los encargados de formularlas, con el objetivo de enfatizar los aspectos considerados de mayor importancia para las personas de la comunidad. De esta manera, la posibilidad de hacer realidad las transformaciones sociales y orientar el contenido de las políticas públicas reside principalmente en los actores partícipes del proceso, y no en agentes externos a la comunidad. De esta manera, se utiliza la intermediación de la imagen visual y las historias que de ella se derivan como evidencia para promover la participación eficaz de las personas inmersas en la problemática investigada, y así no quedan sometidas a las intenciones de otras personas o imágenes.

Para Wang y Burris (1997), el sondeo de naturaleza dialógica que da origen a estos intercambios posibilita el desarrollo de la conciencia crítica -o la concientización, en términos de Freire (1970)-, y se habilita a los participantes a intervenir en su propia realidad.

En el desarrollo de esta metodología, cobra gran importancia que las fotografías sean tomadas por personas de la misma comunidad, a nivel de "la base", sin considerar ningún privilegio jerárquico. Son ellas quienes plasman en cada imagen su propia mirada de la realidad cotidiana que las rodea. Posteriormente, se desarrollan discusiones acerca de las fotografías tomadas y se realiza el análisis crítico de las condiciones sociales que aportan o disminuyen al bienestar personal y colectivo. Para Wang, lo que los expertos piensan que es importante puede no coincidir con lo que las personas de la comunidad consideran que lo es. En este contexto, el conocimiento que surge es práctico y está dirigido hacia la acción (Wang, 2005)1.

El método Photovoice ha tenido un importante desarrollo en temas de salud, que van desde la obesidad infantil hasta la salud materno-infantil y el dolor crónico en adultos mayores (Darbyshire, MacDougall Schiller, 2005; Pies \& Wang, 2004; Baker \& Wang, 2006). También se han tratado temas relacionados con el bienestar social de personas marginadas y se han desarrollado programas para la prevención de la violencia juvenil, entre otros, en distintos lugares de Europa y Norteamérica, principalmente.

De acuerdo con las premisas de Photovoice (Wang \& Burris, 1997; Wang, 2005), este método de investigación busca que las personas utilicen la fotografía para documentar sus vidas, y de esta manera, valida el conocimiento local desde su propia perspectiva y da voz a las comunidades que, tradicionalmente, han sido silenciadas por su condición de marginalidad.

Photovoice es altamente flexible y puede ser adaptado a objetivos específicos de participación, así como a diferentes grupos y comunidades; sin embargo, el hecho de que no siempre se generen resultados inmediatos de alto impacto en la comunidad o que sean sus miembros los encargados de las acciones posteriores puede desanimar o llevar a que el método no sea totalmente apreciado. Además, implica otros riesgos en su aplicación, como la dificultad para interpretar las fotografías, lograr las discusiones y posibilitar las distintas miradas y versiones sobre los temas tratados.

Principalmente, uno de los objetivos de Photovoice es empoderar a los habitantes de una comunidad o a un grupo de individuos como sujetos responsables, capaces de liderar su propio desarrollo, no necesariamente dependientes de ONG u otras organizaciones impulsoras de los cambios o mejoras en ámbitos locales.

1 Adaptación al español de: Photovoice. Social Change through Photography. En línea: http: //www.photovoice.com. Fecha de consulta. 17 de marzo de 2008 


\section{Chaicuriri por el Objetivo: una investigación participativa con Photovoice ${ }^{2}$}

\author{
Nunca pensé que pudiéramos discutir tantas cosas \\ mirando nuestras fotos. \\ Haydee Z. ${ }^{3}$, participante en Chaicuriri por el Objetivo
}

La luz deslumbrante de los flashes de 46 cámaras llenó el aula escolar del Cantón de Chaicuriri ${ }^{4}$. El interior penumbroso y azul pálido del aula abrazó a un número igual de habitantes de la comunidad. Envueltos en mantas de tela hechas en casa para no dejar entrar el aire frío, estos hombres, mujeres, y niños -quienes representaban el $92 \%$ de los habitantes del lugar mayores de nueve años de edad- se habían reunido motivados por un esfuerzo singular que proponía usar la fotografía para documentar cómo percibían las fortalezas y debilidades de su comunidad, y para identificar sus oportunidades de cara al futuro. La mayoría de ellos tenía por primera vez cámaras en sus manos, y no sólo querían capturar la belleza austera de su comunidad, sino que también deseaban revelar fotos que pudieran ser utilizadas, a fin de impulsar diálogos comunitarios, expresar sus necesidades a funcionarios e instituciones gubernamentales y no gubernamentales, e iniciar planes concretos de acción para reforzar el futuro de su comunidad. Al participar en este proceso, que aplica la metodología Photovoice, sus voces, que antes habían sido políticamente marginadas, salieron a la luz durante incontables horas de discusiones y en más de 2.000 fotos.

2 El proyecto Chaicuriri por el Objetivo fue desarrollado por Gregory Spira con la Fundación Kechuaymara, en el altiplano boliviano, entre septiembre y diciembre de 2007, y fue respaldado por el gobierno canadiense, por medio de la Agencia Canadiense de Desarrollo Internacional (CIDA) y su programa "Estudiantes para el desarrollo".

3 No se incluyen los nombres completos de los participantes a fin de proteger su identidad, lo cual fue un requerimiento del Consejo canadiense Tri-Council, que se ocupa de revisar investigaciones para mantener las normas de ética.

4 En lengua aymara, corresponde a un "Ayllu", término que define la división territorial, utilizado por el gobierno local y nacional. También se le denomina Cantón, perteneciente al municipio Caripuyo, en el departamento de Potosí, en el sur de Bolivia.
Según Paulo Freire (1970), la existencia de los seres humanos se sustenta en los deseos simultáneos de nombrar y transformar el mundo que los rodea. Desde los años setenta, los profesionales que trabajan los temas de desarrollo internacional y comunitario han intentado aprovechar estos deseos para realizar cambios sociales en los países en vías de desarrollo. Sin embargo, como lo indica Freire, muchos de sus proyectos han fracasado debido a que, "their authors designed them according to their own personal views of reality, never once taking into account [...] the menin-a-situation to whom their program was ostensibly directed" $^{\prime \prime}$ (Freire, 2000, p. 94). De esta forma, los expertos llegaban a la comunidad conservando su visión "desde afuera" e identificaban prioridades de desarrollo comunitario que no correspondían con la manera en que los habitantes locales percibían los mismos asuntos.

Teniendo en cuenta esto, otros profesionales vinculados a temas de desarrollo recientemente han comenzado a retomar las nociones de Freire acerca de fomentar diálogos auténticos para adelantar proyectos de comunicación participativa que sean planificados, diseñados y finalizados por los miembros de las comunidades. Estos proyectos aprovechan la expresión artística, utilizando frecuentemente fotografías, videografías y piezas de teatro, entre otros, para apoyar a las comunidades que intentan identificar $y$ reflexionar en cuestiones pertinentes a sus realidades (Mead \& Shaw, 2007). Estos proyectos, los cuales son intrínsecamente dialógicos, forman parte del proceso de la comunidad de nombrar el mundo y lograr la realización de cambios sociales.

Al entregar el control de este proceso a los actores locales, los proyectos de este tipo posibilitan que los habitantes se hagan responsables de su propia representación y sean ellos quienes pongan en evidencia su propia mirada frente a su realidad y al concepto

\footnotetext{
$5 \quad$ Traducción de los autores: "sus realizadores partieron de su propia visión personal de la realidad sin tener en cuenta, en ningún instante [...] a los hombres en situación a quienes dirigían, en apariencia, su programa".
} 
de desarrollo que consideran mejor para ellos. Estos esfuerzos participativos dejan ver elementos claves del método pedagógico de Freire, quien plantea que la combinación entre reflexión y acción posibilita la praxis, la cual le permite al participante usar el diálogo para tomar el control y dirigir el desarrollo de la comunidad hacia ella misma. Es más, empleando expresiones artísticas como la fotografía, es posible reforzar las habilidades de las personas a fin de identificar, de un modo activo y creativo, las fortalezas, debilidades y oportunidades de la comunidad.

Por consiguiente, se puede afirmar que las discusiones comunitarias que surgen durante los proyectos participativos que usan el arte y distintas formas de expresión, como las mencionadas anteriormente, refuerzan las habilidades de los miembros de la comunidad para maximizar su capacidad de acción. Esto empodera a las comunidades para identificar cuestiones relevantes para ellas mismas y diseñar soluciones propias (Underwood \& Jabre, 2003). Lo anterior ocurre sobre todo cuando se pide a los participantes que planteen planes de acción comunitaria o realicen evaluaciones participativas, de cara a identificar sus propias necesidades (es el caso de las Evaluaciones Participativas de Pobreza y las Evaluaciones Participativas Rurales).

En las discusiones de grupo, estas herramientas producidas por las comunidades señalan temas que tienen que ver con su desarrollo y establecen los pasos para realizar los cambios que quieren ver. Además, estas evaluaciones participativas señalan quién va a ser responsable de cuáles acciones, cuándo se van a dar los distintos pasos o momentos y dónde se van a adquirir los recursos necesarios (Abah, 2007; Chambers, 2004; Robb, 2001).

El proyecto Chaicuriri por el Objetivo se vale del método de investigación conocido como Photovoice, vinculado a las formas de expresión mencionadas en párrafos anteriores, el cual busca aprovechar la creatividad de los participantes y así trasladar a los actores locales el control de la representación y de la planifi- cación del proceso investigativo, de cara a establecer la noción de desarrollo propia de la comunidad.

A continuación, se presenta la metodología del proyecto Chaicuriri por el Objetivo, en la que se demuestra cómo se puede hacer uso de Photovoice como herramienta efectiva para llevar a cabo una evaluación participativa de las necesidades identificadas por las comunidades. También se presentan extractos fotográficos y los testimonios de los habitantes de Chaicuriri, quienes participaron en el proyecto.

\section{Metodología}

El proyecto Photovoice Chaicuriri por el Objetivo (CPO) fue creado con la finalidad de reforzar el trabajo en liderazgo indígena de la Fundación Kechuaymara ${ }^{6}$, por tanto, se contó con su participación activa en el diseño del proyecto y la selección de la comunidad. Debido a que esta Fundación está conformada por indígenas aymaras, sus percepciones acerca del ambiente cultural de Chaicuriri fueron de gran ayuda. Si no se hubiera alineado el proyecto con las costumbres y las creencias locales el proyecto habría fracasado.

El punto de partida de la experiencia es suministrar cámaras de rollo a los habitantes de la zona (hombres, mujeres y niños), a quienes se les pide hacer un registro fotográfico acerca de su visión de desarrollo. Esta metodología tiene como base teórica el trabajo de Paulo Freire (2000), quien afirma que un grupo de personas que están tratando de empoderarse tienen primero que examinar y reflejar críticamente las condiciones de su mundo; y Photovoice es un modo para que puedan registrar visualmente sus vidas. Posteriormente, se utilizan los resultados para iniciar diálogos comunitarios que tienen el propósito de evidenciar las contradicciones y realidades de su vida social, política y económica. Este sondeo deja como resultado lo que

6 La Fundación Kechuaymara es una organización de desarrollo fundada y liderada por indígenas, cuyo objetivo es la expansión de las libertades universales de las comunidades aymara y quechua en Bolivia. Tomado de documentos oficiales de la Fundación Kechuaymara. En línea: http://www.aymaranet.org/kechuaymara. html Fecha de consulta: 31 de marzo de 2008. 
Freire denomina la "concientización" y empodera a los participantes para surgir como sujetos activos, quienes pueden actuar para orientar su realidad.

El punto de partida de la experiencia es suministrar cámaras de rollo a los habitantes de la zona (hombres, mujeres y niños), a quienes se les pide hacer un registro fotográfico acerca de su visión de desarrollo. Esta metodología tiene como base teórica el trabajo de Paulo Freire (2000), quien afirma que un grupo de personas que están tratando de empoderarse tienen primero que examinar y reflejar críticamente las condiciones de su mundo; y Photovoice es un modo para que puedan registrar visualmente sus vidas. Posteriormente, se utilizan los resultados para iniciar diálogos comunitarios que tienen el propósito de evidenciar las contradicciones y realidades de su vida social, política y económica. Este sondeo deja como resultado lo que Freire denominó la "concientización" y empodera a los participantes para surgir como sujetos activos, quienes pueden actuar para orientar su realidad.

"Photovoice CPO" fue dividido en tres fases distintas, que ocurrieron entre septiembre y diciembre de 2007. A causa de la lejanía de la comunidad de Chaicuriri y el hecho de que se quiso minimizar la interrupción en la vida diaria de los participantes, se tomó la decisión de dividir el proyecto en viajes separados por varias semanas. En cada viaje los investigadores permanecieron entre cuatro y diez días con la comunidad. Las primeras fases duraron más tiempo debido a la necesidad de realizar el entrenamiento fotográfico y lograr establecer relaciones de confianza entre la comunidad y el investigador, denominado facilitador, y su personal de apoyo.

Es importante mencionar que la metodología Photovoice forma parte de la tradición de la Investigación Acción Participativa. Por esta razón, el organizador del proyecto no asume el rol de conductor de la investigación, sino de facilitador, parcialmente distanciado de los grupos de participantes. De este modo, se da la prioridad a las perspectivas de los mismos participantes.
La mayoría de proyectos que usan la metodología Photovoice han usado cámaras desechables, porque en la alfabetización visual que se da a los participantes no es necesario enseñar su funcionamiento. Pero en "Photovoice CPO" se usaron cámaras automáticas de alta calidad por dos motivos: todas las cámaras fueron donadas por ciudadanos canadienses que habían cambiado a cámaras digitales, y por eso estuvo disponible una gran cantidad de cámaras de rollo, descartando la necesidad de comprar cámaras desechables. El segundo motivo tiene que ver con la intención de hacer el proyecto sostenible, considerando que la Fundación Kechuaymara tuvo prevista la ampliación del proyecto a otras comunidades cercanas.

Al inicio del proyecto fue necesario que el personal de apoyo y algunos líderes locales recibieran capacitación en el uso de las cámaras, para luego poder facilitar el entrenamiento a los participantes. Posteriormente, estas personas serían capacitadores, responsables de ayudar con el procedimiento para solucionar problemas durante el desarrollo del proyecto.

La primera fase, con una duración de diez días, centró el énfasis en brindar una introducción a la metodología Photovoice, entrenar al personal de apoyo y a los participantes en los fundamentos fotográficos. El facilitador y los participantes discutieron aspectos relacionados con la ética fotográfica, incluyendo el potencial para causar problemas relacionados con la representación y la posibilidad de falsear la realidad. Se discutió cómo la fotografía pone un poder social en las manos del fotógrafo y se establecieron normas básicas para asegurar la participación respetuosa entre todos los usuarios de las cámaras.

Explicar el funcionamiento técnico de las cámaras y el proceso fotográfico ayudó a que la fotografía fuera menos misteriosa para los participantes. Esto fue esencial, porque solamente seis de los 46 asistentes habían tomado fotos antes. Veintiocho fotógrafos mayores recibieron una cámara para cada uno y un rollo de veinticuatro fotos. Los dieciocho niños, entre tanto, compartieron una cámara y un rollo. 
También se desarrollaron cursos interactivos que trataron los temas de composición e iluminación fotográfica básica. Pero estas sesiones solamente ofrecían información general para no suprimir la creatividad. Además, a causa de que las culturas suelen interpretar las estéticas en modos diferentes (Banks, 2001) y el facilitador fue canadiense, no se quiso incorporar en la comunidad un prejuicio norteamericano acerca de lo que es una foto "bella".

Las tareas fotográficas también fueron diseñadas para no influenciar los temas fotografiados. Las instrucciones iniciales solamente pidieron a los fotógrafos de Chaicuriri sacar fotos de lo que ellos consideraban representativo en la comunidad, de las fortalezas, debilidades y oportunidades para el futuro. Sorpresivamente, surgió la necesidad de aclarar estas instrucciones, porque los conceptos de "fortalezas y debilidades" no existen en la cultura aymara. Al consultar con las personas del lugar fue necesario reformularlos usando la devoción de la comunidad hacia la Pachamama, la "mamá del universo", quien ellos creen está presente en todos los aspectos materiales y espirituales. Haciendo esta traducción cultural fue posible conectar las "debilidades de la comunidad" al concepto de "las cosas que hacen daño a la Pachamama", y las "fortalezas de la comunidad" al concepto de "las cosas que hacen feliz a la Pachamama". Los participantes también documentaron los aspectos de la comunidad que querían cambiar y los aspectos que querían que quedaran iguales.

Al trabajar con personal de apoyo que hablaba lengua aymara fue posible hacer comprensibles estos conceptos para los participantes. La mayoría de ellos también hablaba español, pero si la comunicación hubiera sido solamente en este idioma -considerado muchas veces por pueblos originarios como un idioma colonizadorse podría haber perjudicado el proceso colaborativo y popular que se quería fomentar, así como excluir a los participantes que no hablaban esta lengua. Por estos motivos, siempre se contó con la presencia de un intérprete simultáneo.
Para crear un mejor ambiente de colaboración, los participantes asistieron en grupos de entre seis y diez personas para hacer una lluvia de ideas y pensar en el tipo de cosas que debían fotografiar. Ellos mismos decidieron con quiénes se querían agrupar. En términos generales, se puede decir que se reunieron en grupos basados en vínculos comunales, familiares 0 escolares ya establecidos en la comunidad. A causa de este nivel de intimidad cuando empezaron a discutir sus fotos en las fases siguientes, se sintieron con una gran comodidad. Después de terminar el entrenamiento los participantes pasaron una semana completando las tareas fotográficas.

La segunda fase se inició cuando los participantes recibieron las fotos reveladas. Fue una experiencia emotiva, porque la gran mayoría nunca antes había tenido una foto propia, tomada por ellos mismos. La siguiente tarea fue seleccionar una o dos fotos que para ellos fueran representativas de su visión frente a las fortalezas, debilidades y oportunidades de la comunidad. Tenían que preparar una descripción de las fotos para compartir con los demás en sus grupos. Este proceso siguiente ayudó a los participantes a desarrollar sus discusiones sobre temas amplios que podrían generar análisis, reflexión y planificación colaborativa (Labonte, Feather \& Hills, 1999).

En reuniones con sus grupos, cada participante presentó la foto que decidió describir. Estas reuniones seguían una versión modificada del método llamado "Story/Dialogue" desarrollado por Labonte, Feather y Hills (1999). Con este método, los participantes participan en diálogos estructurados, discutiendo sus interpretaciones personales para identificar asuntos comunes y planear estrategias para actuar. Normalmente se solicitan historias personales que describen experiencias individuales de los participantes. También los facilitadores suelen predeterminar los temas que los participantes tienen que discutir. En el caso de Chaicuriri, en lugar de solicitar cuentos personales, los participantes describieron sus fotos, analizaron el contenido, identificaron el significado general para la comunidad y los temas subyacentes y 
propusieron planes concretos para resolver el problema señalado. Además, se permitió que los participantes generaran los temas amplios de discusión.

Cada fotógrafo de Chaicuriri empezó describiendo los contenidos visibles en su foto. Después, el facilitador hizo preguntas para ayudar al participante a analizarlos con mayor profundidad y explicar por qué tomaron la foto al sujeto u objeto que escogieron y cuáles temas subyacentes querían señalar con ello. A este tipo de preguntas se le llamó "preguntas ¿por qué?”. El facilitador también estimuló a los participantes a explicar por qué pensaron que ese era un asunto importante para la comunidad y de ahí surgieron las "preguntas ¿para qué?". Esto ayudó a los demás en el grupo a indicar cómo esas percepciones de los asuntos fueron diferentes a sus propias percepciones. Este proceso los transformó de oyentes pasivos a participantes activos en un círculo de reflexión (Labonte, Feather \& Hills, 1999). De esta forma, empezaron a analizar críticamente el contexto social en que viven.

Estos diálogos ayudaron al facilitador para involucrar al grupo en el proceso de generar soluciones posibles a los problemas identificados o modos de apoyar las fortalezas señaladas. De esto surgieron las "preguntas ¿ahora qué?". Cada foto presentada por los participantes al grupo siguió estos mismos pasos. De este modo fueron parte de un proceso de empoderamiento educativo, primero desarrollando la conciencia crítica frente a su mundo, y después desarrollando pasos concretos para transformarlo (Freire, 2000).

A fin de fomentar una actitud de escucha activa, se incorporaron varias medidas en los grupos de diálogo. A los participantes se les avisó que tenían que presentar los temas comunes de su grupo a los demás en la comunidad, de manera que cada individuo tenía la responsabilidad compartida de ser portavoz. Al final de la segunda fase, las presentaciones sirvieron como catalizador de discusiones comunales. Para aumentar la escucha activa, al menos un miembro de cada grupo asumió el papel de secretario del grupo, anotando los puntos clave de los diálogos.
Mientras que iban discutiendo las fotos de la primera fase, los participantes seguían tomando otras para mostrar la visión de desarrollo que querían para su comunidad. En la primera fase, el facilitador y su personal de apoyo dirigieron las sesiones de entrenamiento fotográfico; pero en la segunda, el facilitador dejó a los participantes que entre ellos mismos se enseñaran. Los fotógrafos de la comunidad miraron las fotos de la primera fase para identificar lo que funcionó y lo que fracasó en sus composiciones. Juntos identificaron modos efectivos de mostrar temas específicos y solucionaron problemas técnicos.

En esta segunda fase tampoco se instruyó a los participantes en qué tipo de tarea fotográfica tenían que trabajar. Los grupos mismos decidieron, según lo que pensaban que todavía faltaba en su panorama de fortalezas, debilidades y oportunidades de transformación en la comunidad. Al final de estas sesiones de colaboración, los fotógrafos sacaron entre 18 y 36 fotos en seis días. El entrenamiento fotográfico dejó a los participantes como dueños absolutos de los resultados.

Durante la tercera fase, la comunidad se volvió a reunir para discutir las fotos que tomaron durante la segunda fase y para participar otra vez en los círculos de reflexión dialógica. De nuevo, cada fotógrafo seleccionó una o dos fotos para iniciar una discusión de un tema específico, en grupos conformados por un número de seis a diez personas.

En este segundo encuentro de diálogos, el rol del facilitador presentó cambios destacados. Como ya se mencionó antes, durante la primera serie de discusiones el facilitador tenía que guiar activamente a los participantes contestando las preguntas de la metodología "Story/Dialogue" -las preguntas "ipor qué?", "ipara qué?" y "zahora qué?". Pero en estos últimos diálogos el rol del facilitador disminuyó, porque los participantes habían comprendido y apropiado el proceso. Ellos mismos se anticiparon a las preguntas y los temas que fueron importantes para discutir; tomaron el rol de líderes de discusión. Gracias a que 
el facilitador desempeñó un papel menos activo, las discusiones entre los participantes avanzaron de un modo más natural. En consecuencia, los grupos exploraron los temas subyacentes con más profundidad e identificaron más pasos concretos para avanzar en los temas que aportarían a la visión de desarrollo de la comunidad.

Aumentar la conciencia crítica de la comunidad a partir de las discusiones representa solamente uno de los objetivos del método Photovoice. También hace falta reunir los distintos temas y soluciones para presentarlos como las voces del pueblo que antes habían sido marginadas. Aunque el diálogo entre miembros de la comunidad es crucial, hace falta también presentar sus necesidades a los dirigentes políticos y administrativos, quienes pueden apoyar o realizar cambios efectivos en la comunidad (Wang \& Burris, 1997).

Originalmente, se planificó una serie de exposiciones fotográficas, a fin de mostrar las prioridades establecidas por los habitantes de Chaicuriri para impulsar el desarrollo de su comunidad. Los coordinadores del proyecto intentaron invitar a varios funcionarios de organizaciones no gubernamentales y representantes oficiales del gobierno de varios departamentos, pero a causa de la inestabilidad política vivida en Bolivia a finales de 2007, estas exposiciones fueron canceladas. En su lugar, las fotos estarán incluidas en una presentación multimedia registrada en DVD y distribuida a los funcionarios. La Fundación Kechuaymara usará este material para involucrar a los funcionarios gubernamentales y no gubernamentales en discusiones y abogar por las prioridades de desarrollo de la comunidad. Algunos de estos resultados se presentan a continuación ${ }^{7}$.

$7 \quad$ El informe final de esta investigación será entregado en el transcurso de 2008 a la Fundación Kechuaymara y se espera que pueda utilizar los resultados para el desarrollo de proyectos posteriores con la comunidad de Chaicuriri.

\section{Resultados}

Los resultados del proyecto reflejan claramente su esencia dialógica, sobre todo en lo concerniente a la progresión del método Story/Dialogue, que permite evidenciar el proceso desde la descripción de aspectos y la evaluación de la pertinencia de éstos, hasta la identificación de soluciones. Con frecuencia, surgían percepciones divergentes y distintas valoraciones sobre las soluciones; sin embargo, durante la exploración crítica de los temas, los participantes comenzaron a aceptar las razones fundamentales que contribuían a esas divergencias, e incluso llegaron a incorporarlas en los planes de acción que se derivaban de las discusiones, en un ejercicio de comprensión e integración.

Las siguientes líneas presentan las perspectivas de los participantes de Chaicuriri en torno a los modos de fortalecer la agricultura y los recursos naturales, así como las dificultades y las oportunidades encontradas en la diversificación de la economía rural. Además, aparece un vistazo a la vida familiar, sobre todo, en torno al futuro de los niños y a la importancia de la educación. Éstos fueron algunos elementos relevantes que la comunidad señaló en las fotografías, que además ocuparon una proporción importante del tiempo en las discusiones de grupo. Es importante recordar que los resultados presentados no se deben interpretar como las únicas prioridades de la comunidad; también se consideraron en los grupos de discusión otros aspectos en torno a cómo mejorar la salud ganadera (la base más importante de su economía rural), poner freno a la migración urbana, fortalecer la equidad de género y mantener vivas las tradiciones. Estos resultados se deben interpretar, más bien, como una muestra representativa de la esencia y el alcance del método Photovoice.

\section{Fortalecimiento de las actividades agrícolas}

La agricultura a pequeña escala (que garantiza la subsistencia) representa una de las actividades de mayor dedicación para los habitantes de Chaicuriri. A fin de asegurar la reserva adecuada y suficiente de productos alimenticios, la familia entera tiene que trabajar para 
sembrar y cosechar. Siembran los campos con diversas variedades de papas, trigo, cebada y habas. El cultivo, llevado a cabo sobre todo con herramientas manuales y rudimentarias, tiene lugar en campos terraplenados en las laderas, en canchas pequeñas ubicadas en el recinto familiar y, cuando está disponible, en la llanura de los valles. Un fotógrafo de Chaicuriri describió lo siguiente con respecto al trabajo agrícola, con base en su fotografía:
Tiene mucho significado esta foto. El palo sirve para sembrar. Mi esposa, Eulalia, está poniendo semilla y mi hijo está poniendo guano porque se hace las papas mejores. Lo hacemos así porque es nuestra costumbre y sirve bien para levantar la tierra. Pero no avanzamos ni una hectárea en un día sembrando. En esta forma de sembradío se cansa mucho y hay otras formas más eficaces, por ejemplo las máquinas de sembrar. No hemos cambiado antes porque algunas máquinas no sirven en las tierras rocosas que tenemos (Valentín F.) (ver foto 1).

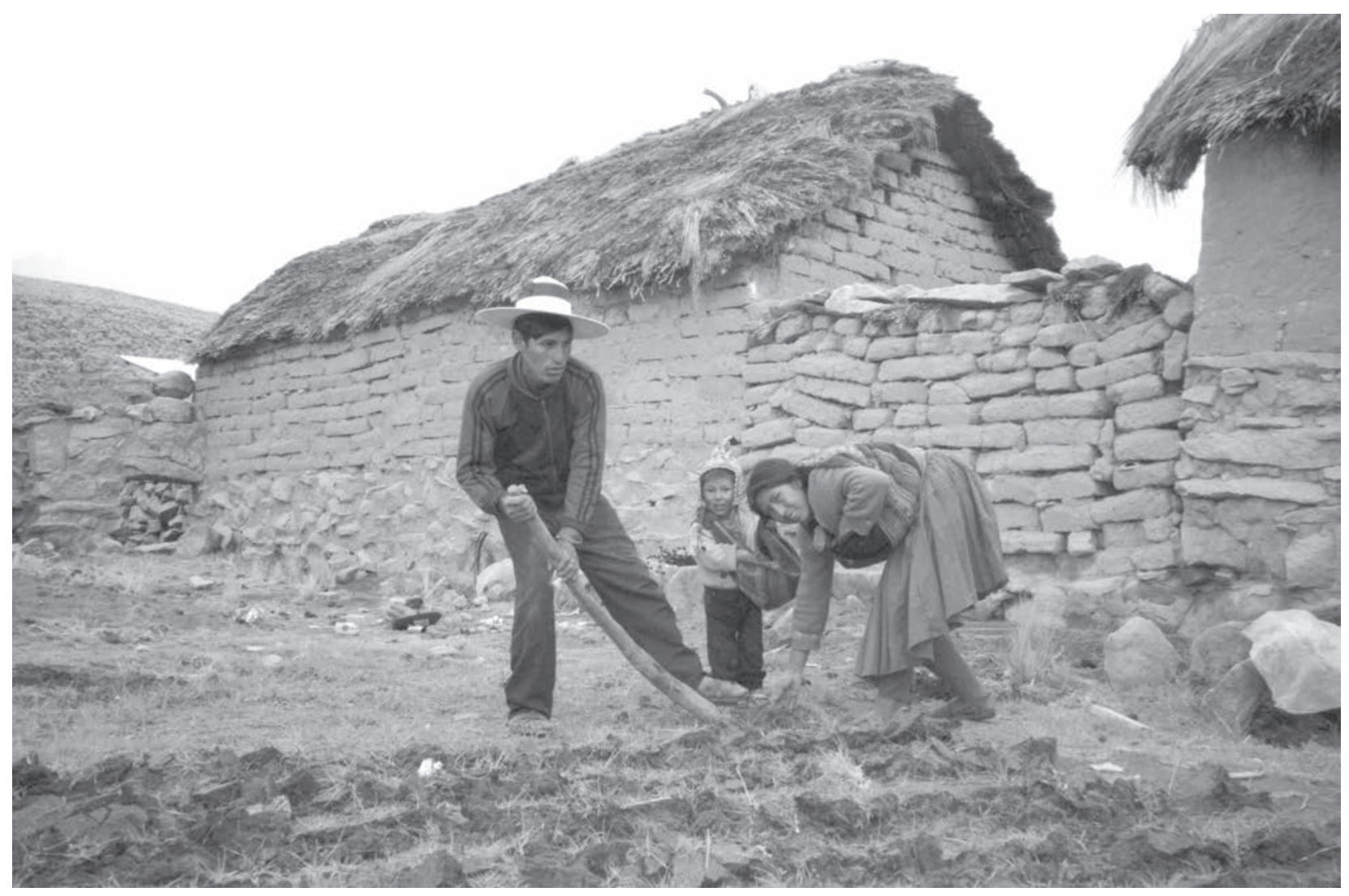

Foto 1. Tomada por Valentín F., el 9 de diciembre de 2007

Con el propósito de acelerar la preparación de la tierra para la siembra, algunas familias emplean toros uncidos y un arado, pero para la gran mayoría resulta demasiado costoso comprar los toros y la herramienta, debido a que el valor de cada toro es equivalente a la ganancia familiar del año entero (ver foto 2). 


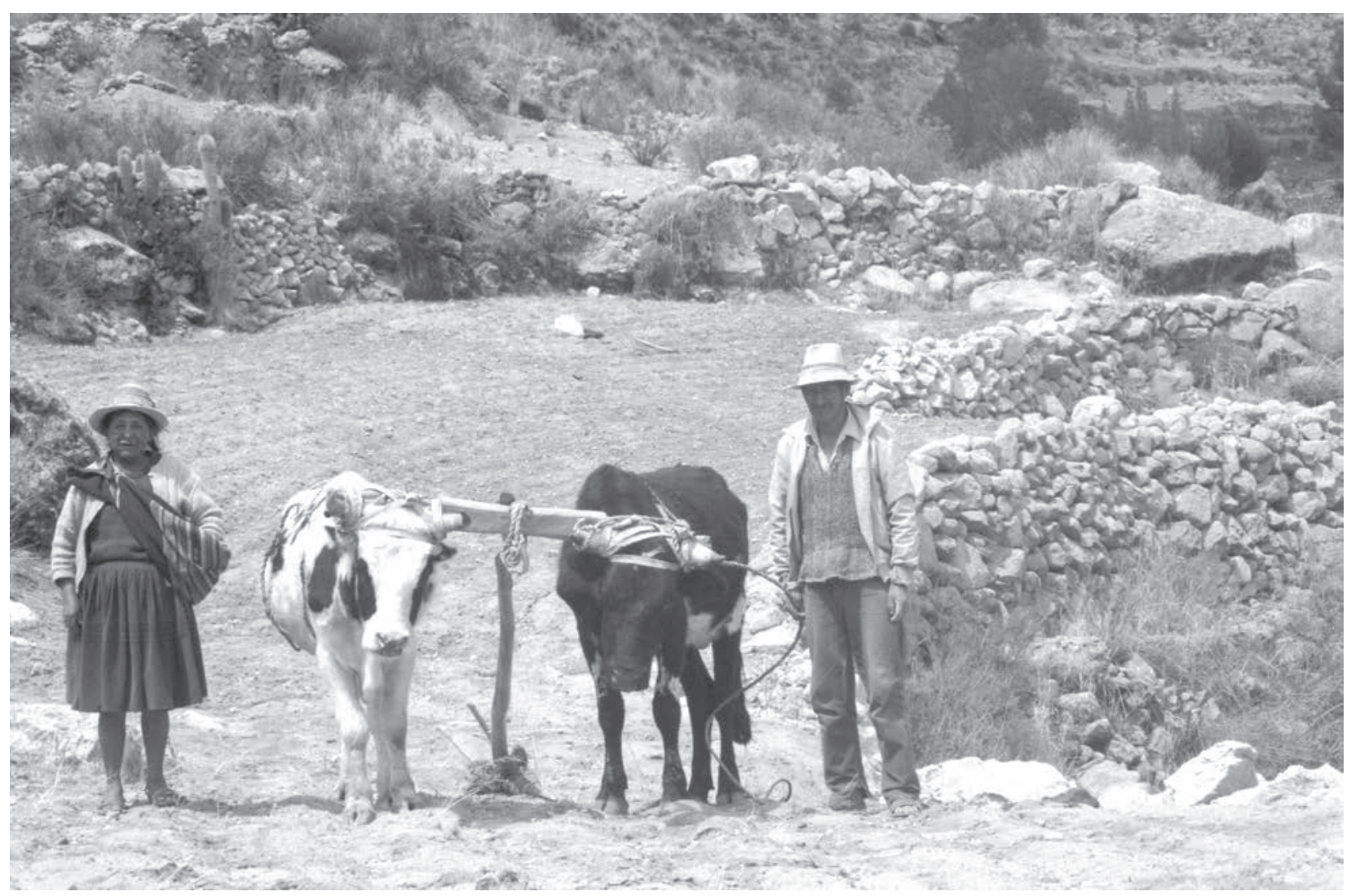

Foto 2. Tomada por Sacarrías C., el 26 de noviembre de 2007

Algunos participantes declararon que el uso de maquinaria para la siembra, o de un tractor, podría aumentar la productividad agrícola, algo que anteriormente la Fundación Kechuaymara y el gobierno boliviano ha apoyado económicamente. Aunque los grupos discutieron la aplicabilidad de esas máquinas en Chaicuriri, al final no llegaron a ponerse de acuerdo en si serían apropiadas. Algunas personas insistieron en que los tractores resultarían inútiles a causa de que "para la llanura necesitan tractores, pero no sirven a causa de las piedras en la tierra; tampoco en las laderas sirven los tractores", como lo expresa Valentín F., mientras que otros pensaron que los equipos aumentarían la eficiencia del trabajo en los campos más productivos, los cuales están ubicados en la llanura de los valles. Este punto requiere una evaluación más extensa para determinar la viabilidad y resolver los desacuerdos.

\section{El uso del lago}

Trescientos metros por encima del pueblo está ubicado un lago de gran altitud, con una superficie aproximada de $4 \mathrm{~km}^{2}$ cuadrados. En la orilla es donde los habitantes de la comunidad secan las papas que cosechan antes de almacenarlas. Como consecuencia, el nombre de la comunidad, Chaicuriri, que significa "el lugar donde se hacen los chuños [papas deshidratadas]" (Feliciano F.). Hasta hace poco, el lago sirvió para la crianza del ganado de la comunidad y fue el hábitat de un número pequeño, pero estable, de peces. Sin embargo, hoy en día, por un bloqueo río arriba, la cantidad de agua disminuyó y la que entra en el lago no es confiable (ver foto 3 ). 


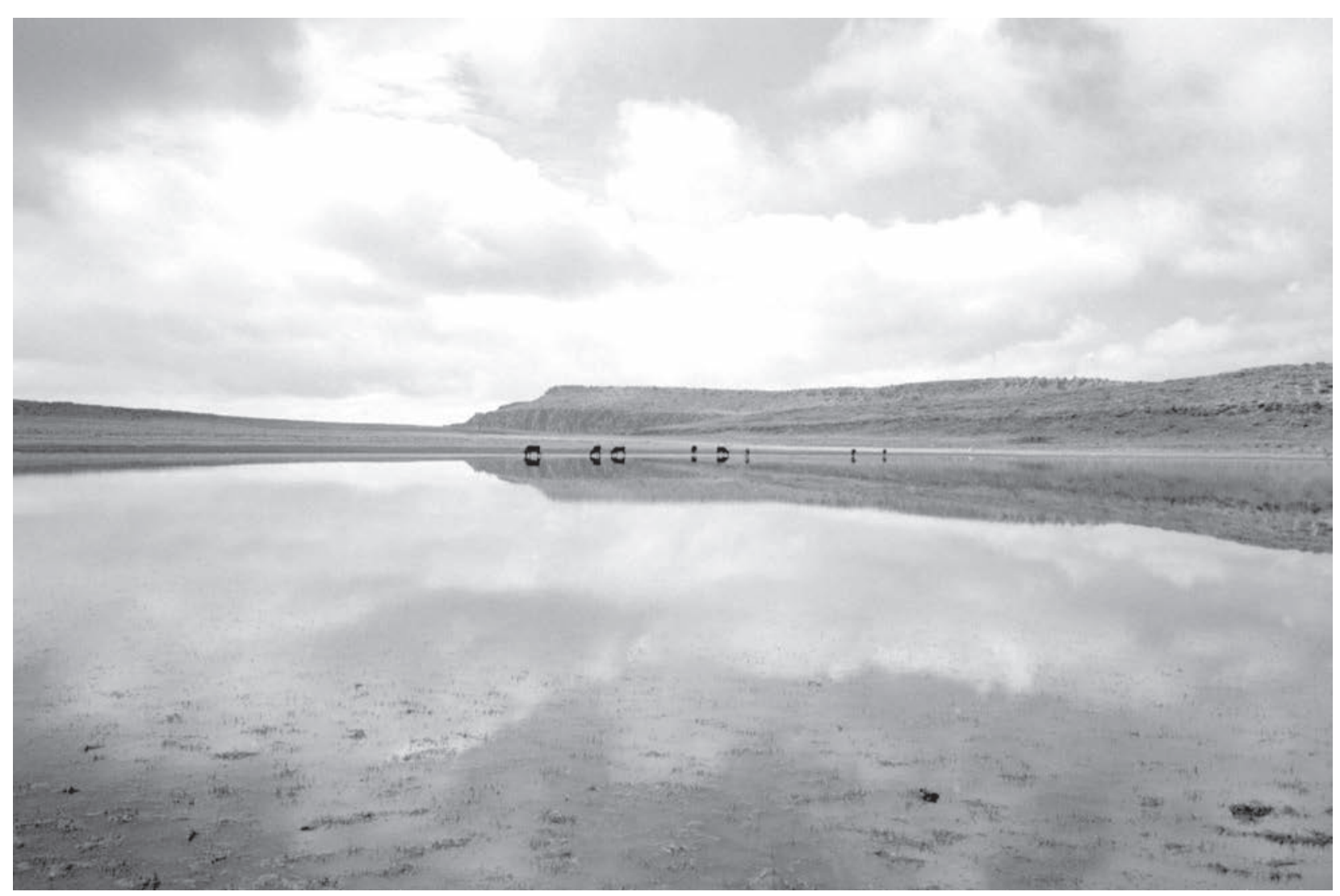

Foto 3. Tomada por Sacarrías C., el 9 de diciembre de 2007

Un habitante de la zona explica así la situación:

\begin{abstract}
La laguna que arriba tenemos antes tenía mucha agua y pescados. Pero ahora han tapado la entrada del agua y está muy bajo el nivel del agua porque el agua sale a otro lugar. Quiero ver el agua entrando otra vez, puede ser con una bomba. Queremos tener el lago para mejorar la economía con pescado y ganado (Trifon S.).
\end{abstract}

Al discutir las consecuencias de la disminución del agua, los participantes comentaron que la lima, una planta acuática oriunda de la zona que era una fuente de alimento importante para las vacas, casi había desaparecido, a causa de los bajos niveles del líquido. Además, el lago se está volviendo cada vez más ácido y la contaminación, debido a la orina de las vacas, que contiene una alta concentración de parásitos, ha incrementado la desaparición de las plantas. Igualmente, los parásitos también llevan enfermedades contagiosas que se pueden pasar entre los animales.
Filiberto F., un participante de los grupos de discusión, sintetizó el problema diciendo: "sin el agua nuestros animales sufren".

Otros participantes comentaron también que el agua contaminada anula la posibilidad de cultivar pescados en el lago; creen que renovando su calidad sería posible llevar a cabo estos cultivos de pescados, que podrían vender en los mercados de centros urbanos, un hecho que diversificaría la base económica de Chaicuriri.

En cuanto al lago, se discutieron otros aspectos como las posibles soluciones a la escasez y la baja calidad del agua, y se determinó que el redireccionamiento del riachuelo que originalmente llenó el lago constituiría la solución que requeriría la más alta inversión laboral. Además, hasta ahora los habitantes no han determinado dónde ni por qué el cauce se desvió, algo que tendrían que establecer antes de excavar un cauce 
nuevo. Asimismo, varias personas propusieron otra solución a más corto plazo, diciendo: "tenemos una visión de llenar el lago, a través de convenios con ONG, trayendo agua de un río. Hay que conseguir una bomba de agua. Queremos una bomba para hacer entrar más agua" (Feliciano F. \& Sacarrías C).

Pero para no agotar este otro río, habrá que evaluar bien esta posibilidad. Sin embargo, se reconoce que es posible que estas soluciones no mejoren la calidad del agua lo suficiente como para permitir el cultivo de pescados en el lago; "queremos poner pescado, pero con las vacas orinando en el agua sería imposible", expresa Filiberto F. Como alternativa, Ios habitantes resolvieron cercar y profundizar otro lago cercano, pero más pequeño, ubicado río arriba. Este mismo habitante afirma: "Quiero investigar cómo podemos profundizar el lago chiquito que hay al lado del lago grande. Tendríamos que cerrar el chiquito a las vacas para tener un lugar para pescados".

Es necesario, entonces, aprovechar el potencial del lago como zona ganadera y pesquera, que proporcionaría la oportunidad de reforzar simultáneamente actividades económicas ya existentes y potenciar otras nuevas. El hecho de que los participantes todavía no han concretado estos planes no se debe considerar como fracaso, sino como representativo del momento formativo en que se encuentra la comunidad frente al proceso de lograr los objetivos propuestos.

\section{Niñez y vida familiar}

Otro de los aspectos en el cual los participantes del proyecto Chaicuriri por el Objetivo también hicieron énfasis fue en la importancia de los vínculos familiares en su vida cotidiana. Al discutir acerca de las amenazas al bienestar de sus hijos, aparecen como las principales las separaciones provocadas por la migración y cuestiones relacionadas con la desigualdad de género. Los habitantes exploraron estos aspectos e identificaron posibles soluciones.

Según las estadísticas de Unicef Bolivia de 2005, la tasa de mortalidad infantil en Chaicuriri y en las comu- nidades vecinas se sitúa cerca del $18 \%$, la más alta de toda América Latina. Los peligros para los niños de la comunidad continúan después del primer año de vida, debido a que están demasiado pequeños para asistir al colegio y a menudo se les deja solos mientras sus padres trabajan en el campo. A través de su fotografía, uno de los maestros de Chaicuriri inició una exploración de este problema.

El niñito se llama Vladimir. Tiene su ruedita solito en la mañana. Es una ruedita de carretilla. Intenta escapar a sus hermanos porque le pegan. Siempre está muy triste y busca un juguete para jugar solito. Está detrás de la muralla de su casa. Como sus hermanos van a la escuela y sus padres van a trabajar el niño siempre lo dejan solo con juguetes que no son verdaderamente juguetes (ver foto 4 ).

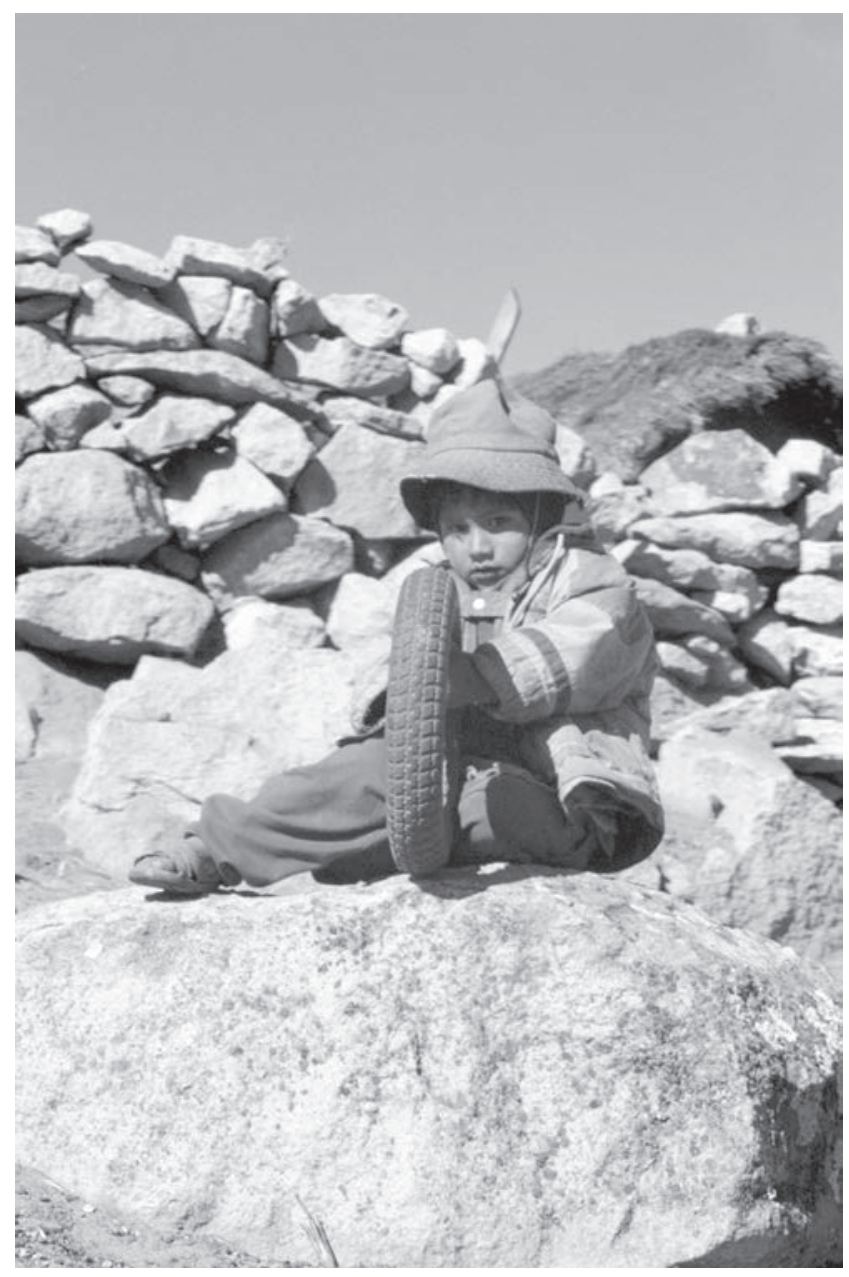

Foto 4. Tomada por Nelson B. 
Posteriormente, los grupos de discusión identificaron los riesgos para los niños y jóvenes y pusieron a prueba su posible impacto en la comunidad. Como lo expresa Feliciano, un habitante del lugar: "Dejar solos a los niños es un problema porque ellos pelean en las calles y también juegan con fósforos. En algunas ocasiones se han incendiado casas haciendo esto".

De acuerdo con lo anterior, Haydee Z., otra profesora de la comunidad, comentó que "algunos de estos niños están perjudicados en las clases por estar solos cuando son niñitos. Tienen más problemas sociales. Estos niños también tienen peor nutrición y peor aprendizaje".

En términos generales, los participantes identificaron dos factores primordiales que contribuyen a que esta situación se presente: la migración masiva de Chaicuriri ha intensificado la demanda de trabajo entre las personas que se quedan y ha generado la disminución en cuanto a la supervisión que los adultos puedan hacer de los niños; $y$ en segundo lugar, los residentes de la zona consideran que existen fallas generalizadas con respecto a las habilidades de crianza de los padres, como lo observó Haydee Z., participante de los grupos de discusión: "Todos nosotros aprendemos de cómo cuidar a animales, pero no aprendemos a cuidar a los niños".

Asimismo, los participantes propusieron dos formas de resolver estos aspectos que tanto les preocupan: decidieron buscar tanto apoyo político como apoyo financiero para facilitar el cuidado de los niños durante el día. De acuerdo con Nelson B.,

Una guardería puede ser una solución, pero tendría que haber una cierta cantidad de niños para hacerla funcionar. Necesitamos también educación para los padres en como criar a niños, sobre todo cuando [...] tienen muchos niños. Puede ser una organización que nos da la educación.

A fin de establecer una guardería, mejorar las condiciones de sus niños, las personas de la comunidad han pensado en buscar una casa que sirva para este fin, y luego comprar juguetes, libros, útiles escolares, entre otros, y pagarle a un maestro.
En cuanto a la educación de los padres para la crianza, los participantes decidieron resolver el asunto de manera colectiva y hablar con las ONG del área interesada en la protección de los niños. Otro de los aspectos relacionados con la infancia que apareció en las discusiones tiene que ver con el reciente reconocimiento en cuanto a la importancia de la educación y, por tanto, a la dedicación al estudio. A pesar de ser oficialmente obligatoria, la enseñanza primaria había recibido un bajo apoyo por parte de la comunidad. Al compartir su fotografía, una madre expresó su deseo de ver a su hija continuar con su educación:

Jimena está yendo a la escuela. Está alistándose para la escuela porque hace falta seguir estudiando, porque cuando lo dejamos no podemos seguir. Sin ir a la escuela no se puede avanzar aquí ni en la escuela. Yo completé solamente educarme en la escuela hasta quinto año de primaria y llegué a conocer cosas que son muy importantes. Quiero que Jimena llegue al menos allí también (ver foto 5).

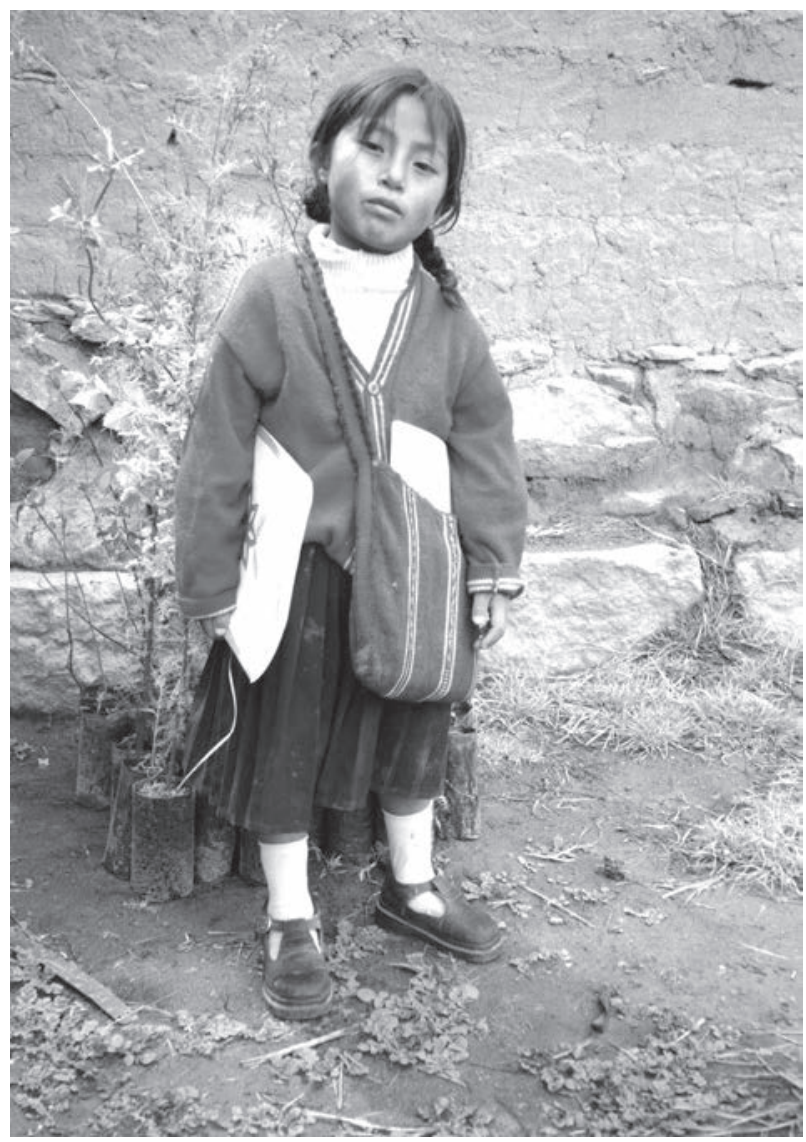

Foto 5. Tomada por Eulalia P., el 9 de diciembre de 2007 
Varios niños asisten ahora a la escuela secundaria y unos pocos adultos han obtenido su grado de secundaria en centros de educación alternativa en la capital regional de Caripuyo. Los miembros de la comunidad que recientemente se graduaron -incluyendo uno de los participantes que está llevando a cabo estudios superiores en atención veterinaria- creen que sus vecinos valorarán aún más la educación avanzada cuando vean que sus compañeros se benefician y a su vez benefician a la comunidad, gracias a sus estudios.

\section{Lo que deja ver la experiencia Photovoice}

La aplicación del método Photovoice en Chaicuriri logró resultados que transcendieron la exposición de representaciones de la vida rural generadas por los mismos participantes; también se superó el hecho de usar las imágenes emotivas para abogar por sus intereses. Ampliando las posibilidades del método Photovoice, las fotos y las discusiones facilitaron a una comunidad entera identificar $y$ analizar temas que querían incluir en su plan de desarrollo comunitario, acordes con su punto de vista y su cosmovisión. En este sentido,

El uso indígena de la cámara otorga autoridad al discurso fotográfico o fílmico, no sólo porque se evita la tendenciosidad, sino porque se ponen en evidencia patrones cognitivos, estilos narrativos $y$ una forma de ordenar el tiempo y el espacio particulares (Collier, 1986, citado en Buxó, 1999, p. 6).

Aunque el método es muy adaptable y transferible a otras comunidades y culturas, los resultados de este proyecto solamente son aplicables para la comunidad de Chaicuriri. Puede ser que otros compartan la valoración de los temas que los participantes en Chaicuriri identificaron, pero este proyecto no pretende presentar los temas como generalizables ni equiparables con otros.

Los facilitadores del proyecto Chaicuriri por el Objetivo intentaron vincular la explicación del método con el ambiente cultural aymara. Los éxitos obtenidos de este esfuerzo corroboran la afirmación en cuanto a que los proyectos que utilizan Photovoice pueden ser desarrollados en diversos ambientes culturales. Así, se evidenció que la adaptabilidad del método, sobre todo como herramienta de evaluación participativa de necesidades, es su máxima fortaleza.

En Chaicuriri, el método Photovoice apoyó a los miembros de la comunidad para llevar a cabo la evaluación participativa de necesidades, la cual estuvo vinculada al proceso de planificación para proyectos futuros de la Fundación Kechuaymara. Esta experiencia tuvo como punto principal destacar el valor de la sabiduría local; por consiguiente, el proyecto intentó evitar las trampas del pasado cuando las agencias de desarrollo no tenían en cuenta las opiniones de las comunidades con las cuales trabajaban, de ahí que en muchas ocasiones se implantaran planes previamente desarrollados antes de llegar a conocer a la comunidad y que deje como resultado la ineficacia o el fracaso del cualquier proyecto. En cambio, al reunir a los actores locales para realizar con ellos el sondeo de sus prioridades, el proyecto Chaicuriri por el Objetivo intentó usar un medio visual para producir un plan detallado de desarrollo, que fuera relevante para la cultura y específico, de acuerdo con el contexto. Comprometidos con el proceso, los fotógrafos de Chaicuriri identificaron prioridades definidas y planes que detallaron paso por paso los actores y las acciones, tanto internos como externos, necesarios para realizar transformaciones sociales en su comunidad.

De manera simultánea al conocimiento de los aspectos favorables de este método, es importante señalar que implementar proyectos participativos no siempre resuelve de manera directa todos los problemas de una sociedad. Como lo afirma White (1994, p. 18): "Los procesos de comunicación participativa no son la panacea para el desarrollo". Este tipo de proyectos no resuelven problemas específicos relacionados con la mortalidad infantil o las fuentes de agua contaminadas; sin embargo, es posible establecer los orígenes de la pobreza y la opresión, lo cual puede significar un aumento en la efectividad de los programas de intervención directa. 
Generalmente, cuando una ONG inicia un trabajo con una comunidad, los participantes esperan obtener beneficios directos, en consecuencia, es necesario, al momento de desarrollar proyectos de comunicación participativa, tener planes concretos para la aplicación de los resultados; por el contrario, si los participantes no ven los resultados de su participación, pueden perder la confianza en sí mismos para actuar y en el proyecto.

En el caso de Photovoice CPO, la Fundación Kechuaymara indicó que tendría en cuenta las prioridades de la comunidad durante las fases de planificación para proyectos futuros $y$, además, compartiría los resultados con ONG y agencias gubernamentales. Los organizadores esperan que las prioridades identificadas influencien a otros trabajos que generen beneficios a la comunidad.

De esta forma, los proyectos que usan métodos como Photovoice posibilitan cambios en las comunidades, sin amenazar la integridad cultural que les subyace. Esto surge porque los acercamientos desde la comunicación participativa para el desarrollo delegan el control de métodos, mensajes y público a actores locales, quienes identifican, dentro de su contexto cultural y social específico, prioridades relacionadas con el cambio, cómo enfrentar oportunidades y obstáculos en la dirección de estos temas, y pensar en la manera para llevar a cabo los cambios precisos. Por tanto, los proyectos de corte participativo facilitan el desarrollo de un marco holístico para la acción de la comunidad, de modo que los grupos marginados puedan elaborar la ruta de su propio camino hacia el desarrollo (Sadanandan Nair \& White, 1994).

\section{Referencias}

Abah, O.S. (2007). Vignettes of Communities in Action: An Exploration of Participatory Methodologies in Promoting Community Development in Nigeria. Community Development Journal, 42 (4), 435-448.
Banks, M. (2001). Visual Methods in Social Research. London: Sage Publications.

Buxó, Ma . J \&.Miguel, J.M. (editores). (1999). De la investigación audiovisual. Barcelona: Proyecto a.

Campo, O. (1998). Nuevos escenarios del documental colombiano. En Pensar el documental. Memorias Seminario Internacional. Bogotá, Ministerio de Cultura.

Cruz C., I. (2007). Nación indígena en la obra de Marta Rodríguez y Jorge Silva. Ponencia en la XII Cátedra Anual de Historia Ernesto Restrepo Tirado. Versiones, subversiones y representaciones del cine colombiano. Investigaciones recientes. Bogotá: Museo Nacional, octubre. Documento sin publicar.

Chambers, R. (2004). Rural Appraisal: Rapid, Relaxed, and Participatory. Participatory Rural Appraisal: Methods and Applications in Rural Planning (Essays in Honour of Robert Chambers) ( $2^{\text {nd }}$ edition, Original work published 1995). New Dehli: Concept Publishing.

Chame, A. \& Demaría M., G. (1998). Fotografía e investigación. La cámara como herramienta de investigación social. Primer congreso virtual de antropología y arqueología. Recuperado de: http: //www.naya.org.ar/congreso/ponencia1-8.htm

Freire, P. (2000). Pedagogy of the Oppressed (original work published 1970). New York: Continuum.

García G., M.E. (2008). La imagen en la investigación social. En P. Páramo (compilador). La investigación en Ciencias Sociales: técnicas de recolección de información. Bogotá: Ediciones Universidad Piloto de Colombia.

García G., M.E. \& Spira, G. (Enero-junio de 2008). Cambiando el rollo: 2.000 fotos para imaginar la 
transformación social. El uso de la imagen en proyectos de investigación social. Miradas, 3 (1).

Jure, C. (2000). La construcción de la alteridad a través de las imágenes. En Ciudad Arqueológica. Ciudad virtual de Antropología y Arqueología. Recuperado de: http://www.naya.org.ar/congreso2000/ ponencias/Cristian_Jure.htm.

Kress, G. \& Van Leeuwen, T. (1996). Reading Images: The Grammar of Visual Design. New York: Routledge.

Labonte, R.; Feather, J. \& Hills, M. (1999). A Story/Dialogue Method for Health Promotion Knowledge Development and Evaluation. Health Education Research: Theory y Practice, 14, 39-50.

Mead, R. \& Shaw, M. (2007). Editorial: Community Development and the Arts: Reviving the Democratic Imagination. Community Development Journal, 42 (4), 413-421.

Robb, C. (2001). Can the Poor Influence Policy?: Participatory Poverty Assessments in the Developing World. Washington, D.C.: World Bank Publications.

Roca, L. (Febrero-marzo de 2004). La imagen como fuente: una construcción de la investigación social. Revista Razón y Palabra, 37. Recuperado de: http://www.razonypalabra.org.mx/anteriores/ n37/Iroca.html

Ruby, J. (1996) Antropología visual. En D. Levinson \& M. Ember (editores). Enciclopedia de Antropología cultural (Vol. 4, pp. 1345-1351). New York: Henry Holt y Compañía. Recuperado de: http://www. antropologiavisual.cl/ART11_IM.HTM

Ruby, J. (Junio de 2007). Los últimos veinte años de antropología visual. Una revisión crítica. Revista chilena de Antropología Visual, 9, 13-36. Recu- perado de: http://www.antropologiavisual.cl/ imagenes9/imprimr/ruby.pdf

Sadanandan N., K. \& White, S. (1994). Participatory development as cultural renewal. In S. White, K. Sadanandan Nair \& J. Ashcroft (editors.). Participatory Communication: Working for Change and Development (138-193). New Delhi: Sage Publications.

Singhal, A. \& Rattine-Flaherty, E. (2006). Pencils and Photos as Tools of Communicative Research and Praxis: Analyzing Minga Perú's Quest for Social Justice in the Amazon. International Communication Gazette, 68 (4), 313-330.

Stohr, W. \& Taylor, F. (editors). (1981). Development from Above or Below? The Dialectics of Regional Planning in Developing Countries. Chichester, NY: J. Wiley.

Underwood, C. \& Jabre, B. (2003). Enabling Women's Agency: Arab Women Speak Out. Conference Papers-International Communication Association Annual Meeting (pp. 1-12). San Diego: International Communication Association.

Wang, C. (2005). Photovoice. Social Changes through Photography. Recuperado de: http://www.Photovoice.com.

Wang, C. \& Burris, M. (1997). Photovoice: Concept, Methodology, and Use for Participatory Needs Assessment. Health Education and Behaviour, 24 (3), 369-387.

White, S. (1994). The Concept of Participation: Transforming Rhetoric to Reality. In S. White, K. Sadanandan Nair, and J. Ashcroft (editors.). Participatory Communication: Working for Change and Development. New Dehli: Sage Publications. 
Zeccheto, V. (2003). La danza de los signos. Nociones de semiótica general. Buenos Aires: La crujía.
Zunzunegui, S. (1989). Pensar la imagen. Madrid: Cátedra. 